\title{
Assessment for Learning in the Chinese Context: Prospective EFL Teachers' Perceptions and Their Relations to Learning Approach
}

\author{
Zhengdong Gan \\ Faculty of Education, University of Macau, Macao, China \\ Fulan Liu \\ Jiangxi Normal University, Nanchang, China \\ Chi Cheung Ruby Yang \\ City University of Hong Kong, Hong Kong SAR, China
}

\begin{abstract}
This study examines how prospective EFL teachers conceive of assessment for learning (AfL) practices and how these perceptions relate to their learning approaches. The study evaluated, in three teacher training universities' in China, 692 prospective EFL teachers' responses to a self-report instrument regarding assessment for learning practices and students' learning approach. Results indicate a significant positive correlation between their perceived AfL experience and their tendency to adopt an achieving or deep approach to learning. Results also reveal that a surface approach to learning was negatively correlated to AfL experience, suggesting that in the Chinese university environment, the more AfL features incorporated into the classroom teaching and assessment processes, the less likely students adopt a surface approach to learning. This study also provides evidence of the potential differences in students' responses to AfL as a result of different institutional environments. Implications of the results for addressing potential barriers to implementation of AfL in the Chinese context are also discussed
\end{abstract}

Index Terms - prospective EFL teachers, assessment for learning, learning approaches, tertiary EFL courses

\section{INTRODUCTION}

Following the review by Black and Wiliam (1998), assessment for learning (AfL) has been strongly promulgated by an increasing number of education systems internationally. In the Asia-Pacific Region, there has been a particular interest in the positive effect of AfL on the learner (Val Klenowski 2009). For example, in Directions for Assessment in New Zealand (Absolum et al. 2009), a clear priority is given to AfL:

all young people should be educated in ways that develop their capacity to assess their own learning. Students who have well developed assessment capabilities are able and motivated to access, interpret, and use information from quality assessment in ways that affirm or further their learning (p. 5).

In Hong Kong, the interest to integrate assessment and teaching brought about a 'learning to learn' curriculum reform emphasizing that teachers provide feedback to students of their strengths and weaknesses as a basis for further improvement in learning (Curriculum Development Council 2001). AfL is explicitly emphasized in an assessment reform document by the Hong Kong government:

All schools should review their current assessment practices and put more emphasis on assessment for learning. The latter is a process in which teachers seek to identify and diagnose student learning problems, and provide quality feedback for students on how to improve their work. Different modes of assessment are to be used whenever appropriate for a more comprehensive understanding of student learning in various aspects (Chapter 5, p. 1, Curriculum Development Council 2002)

Similar assessment innovations are being promoted and carried out in China. The Chinese government has overtly called for assessment reforms that move evaluation systems away from transmission and memorization of 'bookish' knowledge for purely ranking or selection purposes towards more formative, authentic and humanistic approaches to assessment (Chen and Brown 2013; OECD 2011). Although regular high-stakes public examinations are still used extensively to select students at all levels of schooling in China, a new assessment initiative is being carried out in China where a school-based assessment based on the teachers' judgment is to be included in the public examination system. Such curricular policy reform movements attempt to reduce the domineering impact of examinations by placing a greater emphasis on using assessment to inform teaching and learning improvements. For example, the AfL direction in the ongoing curricula reform is clearly reflected in how formative assessment is incorporated and defined in the College English Curriculum Requirements (CECR) (Chinese Ministry of Education 2007). The CECR policy document clearly articulates the need for students to be meaningfully engaged in formative assessment: 
Formative assessment is the procedural and developmental assessment conducted during the process of teaching and learning ... Specifically, it is a means to adapt various assessment approaches and a means to follow up on the teaching and learning process, and to provide timely feedback so as to enhance students' overall development. It facilitates the effective monitoring of students' autonomous learning. Formative assessment includes self-assessment, peer-assessment, and assessment conducted by teachers and school administrators. ... It is used to observe, evaluate and monitor the learning process for the purpose of enhancing effective learning (Chinese Ministry of Education 2007; see also Chen et al. 2013).

While assessment for learning has therefore been vigorously promoted in mainland China and in Hong Kong, so far few empirical studies have been conducted to understand how students' perceptions of AfL practices may relate to their learning approaches. The study reported in this paper is part of a larger research project intended to help us gain a better understanding of the nature of Chinese and Hong Kong university students' perceptions of AfL practices as well as the relationships between these perceptions and their learning approaches. Students participating in the current research were involved in university English language enhancement course, where formative assessment was explicitly recommended and allegedly incorporated into teaching and assessment of the students' learning processes. In the following section, conceptualization of AfL and learning approaches in the literature are reviewed. The research method used and the findings of this study are then presented, and finally, the implications of the results are discussed.

\section{Conceptualization of AfL in the Literature of EducAtional Assessment}

Although assessment for learning has become a widely used concept in educational discourse, a variety of definitions of the term prevail (Klenowski 2009). In light of the review of the research by Black and Wiliam (1998) showing how assessment affects student learning, the Assessment Reform Group (ARG) outlined seven characteristics of assessment that meet the criteria for being considered "assessment for learning":

- It is embedded in a view of teaching and learning of which it is an essential part;

- It involves sharing learning goals with pupils;

- It aims to help pupils to know and to recognize the standards they are aiming for;

- It involves pupils in self-assessment;

- It provides feedback which leads to pupils recognizing their next steps and how to take them;

- It is underpinned by confidence that every student can improve;

- It involves both teacher and pupils reviewing and reflecting on assessment data (ARG 1999, p.7).

Building on these seven characteristics of assessment that promotes learning, a definition of AfL was formulated as follows:

Assessment for Learning is the process of seeking and interpreting evidence for use by learners and their teachers to decide where the learners are in their learning, where they need to go and how best to get there (ARG 2002, p. 2-3).

Primarily, ARG emphasizes that assessment that promotes learning, i.e., AfL, contrasts with tests or examinations intended to certify students' learning. Explicit in the above definition of AfL is thus that AfL is primarily concerned with how assessment is integrated into regular curricular activities, and with how students can be actively involved in the learning and assessment processes (Allal 2010). Although AfL as a term began with the distinction between assessment of learning which is about evaluating what has been learnt and assessment for learning which is about using evaluation to feed into the learning and teaching process and thus improve learning (Gipps 1994; McDowell et. al. 2011), AfL is often formulated as formative assessment/feedback in the literature, as the following quotation illustrates:

Assessment for learning is any assessment for which the first priority in its design and practice is to serve the purpose of promoting students' learning. It thus differs from assessment designed primarily to serve the purposes of accountability, or of ranking, or of certifying competence. An assessment activity can help learning if it provides information that teachers and their students can use as feedback in assessing themselves and one another and in modifying the teaching and learning activities in which they are engaged. Such assessment becomes "formative assessment", when the evidence is actually used to adapt the teaching work to meet learning needs (Black et al. 2004, p. $10)$.

More recently, based on a comprehensive review of the literature (e.g., Sadler 1998; Biggs 2003; Gibbs and Simpson 2005; Black et al. 2003), McDowell et al. (2011) define AfL as an assessment environment that:

- is rich in formal feedback (e.g. tutor comment; self-assessment systems),

- is rich in informal feedback though dialogic teaching and peer interaction,

- provides opportunities to try out and practice knowledge, skills and understanding,

- has assessment tasks which are authentic or relevant,

- assists students to develop independence and autonomy, and

- has an appropriate balance between formative and summative assessment (p. 750).

This formulation of the six core features of an AfL environment, according to McDowell et al., is congruent with a learning culture where assessment encourages students to understand the standards and criteria that embody what it means to do well in the subject and take responsibility for directing their own learning, where assessment engages students through appropriate tasks and provides students with opportunities to test out ideas and practice relevant skills, and where timely feedback from tutors as well as informal feedback through interaction among students themselves is 
available. In light of these six core features of AfL as an assessment environment that can support students' learning, McDowell et al. have further developed a specific AfL inventory known as the Assessment for Learning Questionnaire (AfLQ). In McDowell et al.'s view, the AfLQ was developed to give a broad picture of the ways in which students experience the AfL environments, and thus to provide an indication of the extent to which AfL practices are embedded in classrooms. Their subsequent empirical study in which the AfLQ was used in university classroom settings showed that the AfLQ was sufficiently sensitive to show up the differences between different university courses with or without AfL features.

Most recently, Pat-El et al. (2013) constructed Assessment for Learning Questionnaires for Teachers (TAFL-Q) and for students (SAFLQ) for evaluating perceptions regarding AfL practices in vocational secondary classrooms using matching. The TAFL-Q and SAFL-Q, however, only capture the construct AfL in two subscales: Monitoring and Scaffolding, and fail to cover some of the underlying principles of AfL commonly discussed in the AfL literature such as assisting students to develop independence and autonomy in learning and assessment.

\section{RESEARCH ON STUDENT LEARNING APPROACHES}

Learning approaches have long been recognized as a prerequisite for effective application of learning strategies and as such have been subject to a great deal of research (Birenbaum and Rosenau 2006). From a phenomenographic perspective, the term approach to learning tends to be viewed as a way of characterizing what students say they do (Ellis et al. 2008). Phenomenographic research into approaches to learning has demonstrated that students vary in their approaches to learning at university and that such approaches exhibit qualitative differences (Ellis et al. 2008). In Biggs' (1987) study process model, three approaches to learning (surface, deep and achieving) are proposed. A 'deep' approach to learning is described as striving for improved understanding by applying and comparing ideas, whereas 'surface' learning involves reproductive strategies with little attempt to integrate information (Lizzio et al. 2002). The 'achieving' approach (also referred to as the 'strategic' approach) is characterized by students highly focusing on maximizing the grades earned by their efforts (Ellis et al. 2008). The achieving approach tends to relate to the particular learning context, whereas the deep and surface approaches relate to the content of the material (Birenbaum 2007). While a large body of earlier research has provided empirical evidence for the positive relationship between a deep approach to learning and study success, little research has been done to explore the strong influence of assessment on student learning processes, and how students might be stimulated to use deeper approaches to learning (Gijbelsa and Dochyb 2006).

\section{Methodology}

\section{Participants}

In all, 692 first-year students from two universities in mainland China and one university in Hong Kong took part in this study. Of them, 251 students were from a major teacher training university in Beijing in mainland China (26.7\% were males and $73.3 \%$ were females, mean age 19.06); 309 were from a major provincial teacher training university in Jiangxi Province in mainland China (24.3\% were males and $75.7 \%$ were females, mean age 19.80); and 132 were from a major teacher training university in Hong Kong (17.4\% were males and $82.6 \%$ were females, mean age 20.70) (see Table 1 below). At the time of this study, the participants were involved in a compulsory English language proficiency enhancement course required by each of the universities. The students from mainland China in this study were broadly representative of tertiary students in China in that they were mainly mother-tongue speakers of Mandarin and had entered the university after completing six-year studies in Chinese-medium secondary schools. The Hong Kong students were also generally representative of Hong Kong university students in that they used Cantonese in their daily communication and completed their secondary education in Chinese-medium schools. Both mainland Chinese and Hong Kong students in this study, however, are generally considered to share the same Chinese (i.e. Confucian) cultural traditions (Littlewood 2001).

In mainland China, first-year university students have to take an essentially generic English proficiency course widely known as College English required by the Ministry of Education. This College English program usually aims at developing listening, speaking, reading, writing and translation skills among the students, and is characterized by using a set of unified textbooks approved by the Ministry of Education. The teaching methods are, to a great extent, text-book-based and teacher-centred.

In most universities in Hong Kong, first-year students take a compulsory generic English for Academic Purpose (EAP) course, which tends to focus on general academic reading, writing and speaking. Common activities in EAP classes include teacher input and student group or pair work involving presentations or discussions. 
TABLE 1.

SAMPLE OF THE STUDY.

\begin{tabular}{lcccc}
\hline & $\begin{array}{c}\text { Total } \\
(N=692)\end{array}$ & $\begin{array}{c}\text { Beijing } \\
(N=251)\end{array}$ & $\begin{array}{c}\text { Jiangxi } \\
(N=309)\end{array}$ & $\begin{array}{c}\text { Hong Kong } \\
(N=132)\end{array}$ \\
\hline Male & 165 & 67 & 75 & 23 \\
Female & 527 & 184 & 234 & 109 \\
Mean age (std) & $19.7(1.72)$ & $19.06(.82)$ & $19.80(1.15)$ & $20.70(3.07)$ \\
& & & & \\
\hline
\end{tabular}

Instrument

Based on the six defining features of AfL as an assessment environment stated earlier, McDowell et al. (2011) developed Assessment for Learning Questionnaire (AfLQ) to explore university students' experience of AfL and evaluate the extent to which AfL principles are implemented in different university courses. The AfLQ contains closed-ended rating scales (Visser, Krosnick and Lavrakas 2000) of two constructs (i.e., perceived AfL experience and student approaches to learning). The first construct, perceived AfL experience, has 3 underlying factors: 1) Staff support and module design; 2) Engagement with subject matter; 3) Peer support. The second construct, students' approaches to learning, has 2 underlying factors: 1) Deep approach; 2) Surface approach. The AfLQ thus provides data both on features of course experience related to AfL and on student approaches to learning, which fits well with the purpose of the present research. Consequently, for the questionnaire in this study, we adopted most of the questions in McDowell et al.'s questionnaire that we found applicable both in the Chinese and Hong Kong university context and in English language learning settings as this study focused on student AfL experience in university English language enhancement courses. In addition, a few question items in our questionnaire were drawn from Biggs (1987), Pintrich and De Groot (1990), and Gibbs and Simpson (2004).

The 34-item questionnaire in this study uses a five-point Likert-type scale in which $1=$ strongly disagree and $5=$ strongly agree. The questions in the questionnaire for this study were written in English. Given the fact that the first language of the mainland Chinese students in this study was Mandarin, and the first language of the Hong Kong students in this study was Cantonese, we believed it best to present the questionnaire bilingually to the students in this study. Hence, the questions were translated into Mandarin and Cantonese versions respectively by colleagues from mainland China and Hong Kong. To further ensure the validity of the questionnaire, the Mandarin and Cantonese versions were independently translated back into English by two bilingual researchers to see whether anything could be misinterpreted. The four translators then met to discuss their translations and reach consensus on the Mandarin and Cantonese versions. In addition, one class of students the lead author was teaching were invited to fill in the questionnaire and to comment on the questions. Based on their input, we made some slight changes to the wording of some items. This process helped to ensure that the questions in the questionnaire matched the research focus and the wordings were appropriate to both mainland Chinese and Hong Kong students involved in this study.

The questionnaires were distributed to students by their English teachers in normal class time at each of the three universities. Before distribution of the questionnaire, the students were told that the questionnaire was anonymous, and they were also assured that their responses would not affect their status in their English courses.

Method of analysis

While the questionnaire used in our study is based on McDowell et al.'s (2011) AfLQ, it is nonetheless distinctive in that a few question items in our questionnaire were drawn from other sources such Pintrich and De Groot (1990), and Gibbs and Simpson (2004). Because our questionnaire has a clear theoretical lineage, confirmatory rather than exploratory factor analysis, was conducted to test whether students' responses could be clearly differentiated into the expected underlying dimensions. Pearson correlation analyses were conducted to understand the relationship between students' approaches to learning and their perceptions of AfL practice. In order to see whether perceptions of the AfL practice and learning approaches were significantly different between the three Chinese populations, a MANOVA was conducted.

\section{RESUlts}

SPSS was used for processing and analyzing the quantitative data. Using factor analysis allowed us to condense the underlying dimensions or constructs to three categories of AfL experience and three categories of learning approaches (see Table 2 below). The three factors of AfL experience were: 1) Engagement with subject matter (Cronbach's alpha coefficient .80); 2) Teacher feedback and support (Cronbach's alpha coefficient .812); 3) Collaborative and independent learning (Cronbach's alpha coefficient .644). The three factors of learning approaches were: 1) Surface approach to learning (Cronbach's alpha coefficient .664); 2) Achieving approach to learning (Cronbach's alpha coefficient .580); 3) Deep approach to learning (Cronbach's alpha coefficient .644). These factors generally confirm both the AfL and student learning approach dimensions or constructs reported in McDowell et al.'s (2011) study, providing further empirical evidence concerning the conceptual structure of the questionnaire. In addition, the Cronbach alphas fall within an acceptable range compared with similar previous studies (Birenbaum 2007, Ellis et al. 2008, Furnham et al. 2011) 
Table 3 and Figure 1 below present the means and standard deviations for the different scales of the questionnaire for each of the three groups of students involved in this study. Firstly, when looking at all the study participants (N=692), with regard to students' AfL experience, students agreed more strongly with collaborative and independent learning and teacher feedback and support than engagement with subject matter. The two aspects of AfL, i.e., collaborative and independent learning and teacher feedback and support appeared to be both generally well perceived within Beijing and Hong Kong groups. Within the Jiangxi group, collaborative and independent learning appeared to be their major preferred AfL practice. With regard to students' approaches to learning, it is clear that deep learning approach was least positively perceived within each of the three groups, and all the students appeared to rely more on achieving approach and surface learning approach than deep learning approach. Secondly, all the three groups perceived achieving approach fairly positively. Thirdly, the Hong Kong group demonstrated a greater preference towards surface learning approach.

TABLE 2.

QUESTIONNAIRE SCALES, NUMBER OF ITEMS, AND RELIABILITY COEFFICIENTS (FOR THE ENTIRE SAMPLE IN THIS STUDY

\begin{tabular}{lcc}
\hline Scale & number of items & Cronbach's $a$ \\
\hline Engagement with subject matter & 5 & .80 \\
Teacher feedback and support & 6 & .812 \\
Collaborative and independent & 3 & .644 \\
learning & 4 & .664 \\
Surface approach to learning & & .580 \\
Achieving approach to learning & 5 & .644 \\
Deep approach to learning & 3 & \\
\hline
\end{tabular}

TABLE 3.

MEAN, STANDARD DEVIATIONS FOR THE DIFFERENT SCALES OF THE QUESTIONNAIRE IN THIS STUDY.

\begin{tabular}{|c|c|c|c|c|}
\hline & $\begin{array}{c}\text { Mean } \\
(\mathrm{Std}) \\
\text { Total } \\
(\mathrm{N}=692)\end{array}$ & $\begin{array}{c}\text { Mean } \\
(\mathrm{Std}) \\
\text { Beijing } \\
(\mathrm{N}=251)\end{array}$ & $\begin{array}{c}\text { Mean } \\
(\mathrm{Std}) \\
\text { Jiangxi } \\
(\mathrm{N}=309)\end{array}$ & $\begin{array}{c}\text { Mean } \\
\text { (Std) } \\
\text { HongKong } \\
(\mathrm{N}=132)\end{array}$ \\
\hline Engagement with subject matter & $\begin{array}{c}3.186 \\
(.686)\end{array}$ & $\begin{array}{l}3.309 \\
(.659)\end{array}$ & $\begin{array}{l}3.158 \\
(.626)\end{array}$ & $\begin{array}{l}3.105 \\
(.825)\end{array}$ \\
\hline Teacher feedback and support & $\begin{array}{c}3.496 \\
(.618)\end{array}$ & $\begin{array}{l}3.612 \\
(.516)\end{array}$ & $\begin{array}{l}3.387 \\
(.607)\end{array}$ & $\begin{array}{l}3.548 \\
(.753)\end{array}$ \\
\hline Collaborative and independent learning & $\begin{array}{c}3.672 \\
(.583)\end{array}$ & $\begin{array}{l}3.598 \\
(.581)\end{array}$ & $\begin{array}{l}3.764 \\
(.548)\end{array}$ & $\begin{array}{l}3.652 \\
(.637)\end{array}$ \\
\hline Surface approach to learning & $\begin{array}{c}3.323 \\
(.737)\end{array}$ & $\begin{array}{l}3.264 \\
(.729)\end{array}$ & $\begin{array}{l}3.226 \\
(.727)\end{array}$ & $\begin{array}{l}3.654 \\
(.654)\end{array}$ \\
\hline Achieving approach to learning & $\begin{array}{c}3.586 \\
(.481)\end{array}$ & $\begin{array}{l}3.526 \\
(.471)\end{array}$ & $\begin{array}{l}3.643 \\
(.462)\end{array}$ & $\begin{array}{l}3.586 \\
(.510)\end{array}$ \\
\hline Deep approach to learning & $\begin{array}{l}3.067 \\
(.655)\end{array}$ & $\begin{array}{l}2.981 \\
(.650)\end{array}$ & $\begin{array}{l}3.001 \\
(.621)\end{array}$ & $\begin{array}{l}3.333 \\
(.622)\end{array}$ \\
\hline
\end{tabular}

TABLE 4.

THE CORRELATION COEFFICIENTS FOR LEARNING APPROACHES AND STUDENTS' PERCEPTIONS OF AFL PRACTICE (N=692).

\begin{tabular}{|c|c|c|c|c|c|c|}
\hline & 1 & 2 & 3 & 4 & 5 & 6 \\
\hline 1.Engagement with subject matter & 1 & $.606^{* *}$ & $-.135^{* *}$ & $.392^{* *} *$ & $.304 * *$ & $.203 * *$ \\
\hline 2.Teacher feedback and support & & 1 & -.067 & $.343^{* *}$ & $.271 * *$ & $.179 * *$ \\
\hline 3.Surface approach to learning & & & 1 & .019 & -.037 & -.031 \\
\hline 4.Achieving approach to learning & & & & 1 & $.357 * *$ & $.294 * *$ \\
\hline 5.Collaborative and independent learning & & & & & 1 & $.156^{* *}$ \\
\hline 6.Deep approach to learning & & & & & & 1 \\
\hline
\end{tabular}


TABLE 5 .

THE CORRELATION COEFFICIENTS FOR LEARNING APPROACHES AND STUDENTS' PERCEPTIONS OF AFL PRACTICE IN BEIJING (N=251)

\begin{tabular}{lcccccc}
\hline & 1 & 2 & 3 & 4 & 5 & 6 \\
\hline 1.Engagement with subject matter & 1 & $.566^{* *}$ & -.096 & $.468^{* *}$ & $.398^{* *}$ & $.312^{* *}$ \\
2.Teacher feedback and support & & 1 & -.027 & $.408^{* *}$ & $.311^{* * *}$ & $.246^{* * *}$ \\
3. Surface approach to learning & & & 1 & -.027 & -.001 & -.102 \\
4.Achieving approach to learning & & & & 1 & $.364^{* *}$ & $.313^{* *}$ \\
5.Collaborative and independent learning & & & & 1 & $.306^{* *}$ \\
6.Deep approach to learning & & & & & 1 \\
\hline
\end{tabular}

TABLE 6.

THE CORRELATION COEFFICIENTS FOR LEARNING APPROACHES AND STUDENTS' PERCEPTIONS OF AFL PRACTICE IN JIANGXI (N=309)

\begin{tabular}{lcccccl}
\hline & 1 & 2 & 3 & 4 & 5 & 6 \\
\hline 1.Engagement with subject matter & 1 & $.539^{* *}$ & -.114 & $.347^{* *}$ & $.232^{* *}$ & $.207^{* *}$ \\
2.Teacher feedback and support & & 1 & $-.117^{* *}$ & $.302^{* *}$ & $.316^{* *}$ & $.111^{*}$ \\
3. Surface approach to learning & & & 1 & .003 & .001 & -.080 \\
4.Achieving approach to learning & & & 1 & $.383^{* *}$ & $.298^{* *}$ \\
5.Collaborative and independent learning & & & & 1 & .061 \\
6.Deep approach to learning & & & & & & 1 \\
\hline
\end{tabular}

TABLE 7.

THE CORRELATION COEFFICIENTS FOR LEARNING APPROACHES AND STUDENTS’ PERCEPTIONS OF AFL PRACTICE IN HONG KONG (N=132)

\begin{tabular}{lcccccc}
\hline & 1 & 2 & 3 & 4 & 5 & 6 \\
\hline 1.Engagement with subject matter & 1 & $.753^{* *}$ & $-.212^{*}$ & $.431^{* *}$ & $.365^{* * *}$ & $.261^{* *}$ \\
2.Teacher feedback and support & & 1 & -.107 & $.452^{* *}$ & $.269^{* *}$ & $.251^{* *}$ \\
3. Surface approach to learning & & & 1 & .163 & -.132 & -.043 \\
4.Achieving approach to learning & & & & 1 & $.252^{* *}$ & $.297^{* *}$ \\
5.Collaborative and independent learning & & & & 1 & .146 \\
6.Deep approach to learning & & & & & 1 \\
\hline
\end{tabular}

When looking at all the study participants $(\mathrm{N}=629)$, the results indicate a significant positive correlation between all aspects of AfL practice and two of the three learning approach factors (i.e., achieving or deep approach to learning) (see Table 4). For example, there was a significant positive correlation between teacher feedback and support, collaborative and independent learning and students adopting an achieving or deep approach to learning. This means that students taking an achieving or deep approach to learning may be generally inclined to make greater use of various AfL features in their learning settings. Interestingly, the results also revealed that a surface approach to learning was negatively correlated to all aspects of AfL practice. For example, there was a significant negative correlation between surface approach to learning and engagement with subject matter. It is thus possible that in the Chinese and Hong Kong university learning environment, the more AfL features incorporated into the classroom teaching and assessment processes, the less likely students adopt a surface approach to learning.

To see whether the mean scores in perceptions of the AfL practice and learning approaches were significantly different between the three groups, a MANOVA was conducted. The results indicate that the three groups differed significantly on AfL experience and learning approaches $(F(12,1264)=11.26, p<.001)$. With regard to AfL practice, the results indicate that Beijing (mean 3.309) scored significantly higher than both Jiangxi (mean 3.158) and Hong Kong (mean 3.105) on engagement with subject matter; Beijing (mean 3.612) scored significantly higher than Jiangxi (mean 3.387) on Teacher feedback and support, and Jiangxi also cored significantly lower than Hong Kong (mean 3.548) on this factor. In terms of collaborative and independent learning, Jiangxi (mean 3.764) scored significantly higher than Beijing (mean 3.598); Jiangxi was also higher than Hong Kong (mean 3.652) on this factor but the differences did not reach significance level. With regard to learning approaches, Hong Kong (mean 3.654) differed significantly from Beijing (mean 3.264) and Jiangxi (mean 3.226) on surface learning approach; Jiangxi (mean 3.643) was significantly higher than Beijing (mean 3.526) on achieving approach; finally, Hong Kong (mean 3.333) differed significantly from both Beijing ( mean 2.981) and Jiangxi (mean 3.001) on deep learning approach.

Within the three groups, the patterns of relationships between approaches to learning and AfL factors somewhat varied. For example, Hong Kong group was characterized by demonstrating a strong positive relationship between an achieving approach to learning and aspects of AfL practice such as engagement with subject matter and teacher feedback/support (see Table 7). Compared with Beijing and Hong Kong, Jiangxi was characterized by the lowest-level correlation between deep approach to learning and AfL practice, but Jiangxi demonstrated stronger correlation between an achieving approach to learning and one AfL factor, i.e., collaborative and independent learning (see Table 6). Among the three groups, Beijing demonstrated the most robust positive correlation between a deep approach to learning and most aspects of AfL practice (see table 5). 


\section{DISCUSSION}

The data in this study show that all participants responded fairly positively to collaborative and independent learning, suggesting that students might rationalize collaboration and autonomy as part of their classroom experience and hence consider these aspects of AfL practice a crucial part of learning. The formulation of such perceptions could be related to the current ongoing quality education campaign as part of curricula reform in the educational sector in both mainland China and Hong Kong. An important emphasis of this quality education campaign is that learning and assessment need to enable students to take responsibility for directing their own learning and interact with their fellow students to share and broaden ideas and learning strategies. The finding thus seems to bear out the research on the impact of AfL practice on the development in students of 'meta-cognition' and the ability to gain control over their own learning (Steadman 1998; Gibbs and Simpson 2005), and challenge an assumption frequently put forward in the literature that Chinese students rely on their teacher as the ultimate authority and only valuable source of learning.

Gibbs and Simpson (2005) emphasize that students need appropriate feedback on performance to benefit from courses. Learning and assessment environment thus needs to provide students with frequent opportunities to receive suggestions for improvement. Unlike traditional assessment practices that are usually good at evaluation but fail to provide students with advice and support to improve their own learning (Brown 1999), a major characteristic of AfL is teachers providing students with the skills and strategies for taking the next steps in their learning. Among the three groups of participants in this study, the Beijing and Hong Kong students demonstrated a good level of endorsement of teacher feedback and support, suggesting that good effort was probably placed by lecturers into giving feedback to students in the English language enhancement courses in these two universities. The findings also show that Jiangxi group perceived teacher feedback and support significantly less positively. A possible explanation is that teachers involved in teaching this group of students were less experienced in integrating this aspect of AfL within classroom teaching and learning than teachers in the other two universities. An important way in which AfL can be effectively implemented in classrooms is to ensure that teachers need to be proficient in using a range of assessment techniques in the classroom. Wiliam and his colleague (Wiliam and Thompson 2008, Wiliam 2011) outline five teacher-oriented formative strategies that are essential to AfL integration within teaching and learning processes: 1) Clarifying and sharing expectations and assessment criteria; 2) Designing learning situations that elicit evidence of student understanding; 3) Providing constructive feedback; 4) Activating students as resources for each other in their learning; 5) Activating students as owners of their own learning. Given such an important role of teachers in the enactment of AfL in classrooms, the above result suggests a need to develop teachers' capacity for integrating various forms of AfL practice into their classrooms through effective professional development.

Previous research suggests that in universities, a common practice that promotes AfL is through design of assessment tasks which result in high-quality learning and which students find authentic and relevant as these tasks give them a sense that they are learning something valuable to their long-term personal development (Biggs 2003; Swaffield 2011). In this study, all participants perceived engagement with subject matter less positively than other aspects of AfL practice. Such less positive perception might be shaped by students' own experiences of learning and teaching practices in university English enhancement classes where students might have little opportunity to experience problem-based learning or real world' tasks requiring students to demonstrate their knowledge and skills in meaningful contexts.

Most interestingly, this study provides clear-cut evidence on the relationships between the student experience of AfL and their approaches to learning. All aspects of students' perceived AfL experience (i.e., teacher feedback and support, collaborative and independent learning, and engagement with subject matter) were significantly positively correlated to two of the three learning approach factors, i.e., achieving or deep approach to learning. The results also show that there was a negative correlation between a surface approach to learning and all the three aspects of AfL practice. Particularly worthy to mention is that surface approach to learning was significantly negatively correlated to engagement with subject matter. This is in the context of an assessment reform agenda in mainland China and in Hong Kong that has focused on 'assessment for learning' rather than 'assessment of learning'. The statistics here suggest a clear alignment between perceived AfL experience and students tending to adopt achieving or deep learning approaches. This clear alignment between AfL practice and quality learning approaches thus provides support to the case for making assessment for learning the prime target in the ongoing curricular assessment reform both in mainland China and in Hong Kong. Such outcome can also be useful in persuading skeptics of the value of AfL practices, and in this sense promotion of AfL can contribute to pedagogic change and learning quality enhancement. In McDowell et al.'s (2011) study, they found that within courses in which AfL features were embedded, there was a higher level of use of deep approaches to learning among students when compared with courses that had not used AfL approaches. They also found that students who scored more highly on the deep approach were more positive with regard to staff support, and reported a higher level of engagement with subject matter. This study thus supports McDowell et al.'s earlier observation.

\section{CONCLUSION}

Previous research shows that context is a powerful influence on students' perceptions about assessment environment. The majority of research studies on students' perceptions of university assessment environment have so far been 
conducted in western societies. Drawing on these studies of students' experience of learning assessment conducted in western societies, this study investigates in three Chinese populations involved in university English language enhancement courses: a) students' perceptions of AfL practice; b) the relationships between students' perceptions of AfL practice and their learning approaches. The study documents a clear alignment between perceived AfL experience and tendency to adopt achieving and deep learning approaches among the students. The study suggests that there is variation in the extent to which AfL practices might have been implemented in English enhancement courses across three different mainland China and Hong Kong universities. Different aspects of AfL practice also revealed different perceived levels of endorsement among the students in these universities. It is hoped that this understanding can help to understand the extent to which AfL practice, as proclaimed in ongoing curricula reform in both mainland China and Hong Kong, is effective in promoting students' learning in university classrooms. Significantly, the findings of this study point to the importance of effective professional development that is essential to teachers' acquisition of the capability to provide constructive feedback and promote students' active engagement in learning and assessment activities. The study thus forms a basis for further research on potential barriers to the integration of AfL within university classroom teaching and learning. It needs to be pointed out that this study has not investigated teachers' actual classroom AfL practices in the university environment. To what extent students' perceptions mirror actual practices is therefore not known. Additional qualitative observational research in classrooms is therefore needed to verify students' experience of classroom assessment practices and to obtain a fine-grained understanding of the effects of AfL practices on student learning in different disciplines.

\section{ACKNOWLEDGEMENTS}

I would like to thank the students who participated in this study. I am also grateful to Professor Gu Chuanhua for his assistance in the factor analysis of the data.

\section{REFERENCES}

[1] Absolum, M., L. Flockton, J. Hattie, R. Hipkins, \& Reid, M. (2009). Directions for assessment in New Zealand. Wellington: Ministry of Education.

[2] Allal, L. (2010). Assessment and the Regulation of Learning. In Penelope P, Eva B, \& Barry M (Eds.), International Encyclopedia of Education (pp. 348-352). Oxford: Elsevier

[3] Assessment Reform Group. (1999). Assessment for Learning: Beyond the Black Box. Cambridge, UK: University of Cambridge School of Education.

[4] Assessment Reform Group. (2002). Assessment for learning. Retrieved on 12 December 2016 from http://arrts.gtcni.org.uk/gtcni/handle/2428/4617.

[5] Biggs, J. (1987). The Study Process Questionnaire manual. Victoria: Australian Council for Educational Research.

[6] Biggs, J. (2003). Teaching for quality learning at university: What the student does? Maidenhead: Open University Press.

[7] Birenbaum, M. (2007). Assessment and instruction preferences and their relationship with test anxiety and learning strategies. Higher Education, 53, 749-768.

[8] Birenbaum, M., \& Rosenau, S. (2006). Assessment preferences, learning orientations, and learning strategies of pre-service and in-service teachers. Journal of Education for Teaching: International Research and Pedagogy, 32, 213-225.

[9] Black, P., Harrison, C., Lee, C., Marshall, B., \& Wiliam, D. (2004). Working inside the black box: Assessment for learning in the classroom. Phi Delta Kappan 86(1), 8-21.

[10] Broadfoot, P., Daugherty, R., Gardner, J., Harlen,W., James, M., \& Stobart, G. (2002). Assessment for learning: 10 principles. Cambridge, UK: University of Cambridge School of Education.

[11] Brown, S. 1999. Institutional strategies for assessment. In S. Brown and A. Glasner (Eds.), Assessment Matters in Higher Education: Choosing and Using Diverse Approaches (pp. 3-13). Buckingham: Open University Press.

[12] Buhagiar, M. A. (2007). Classroom assessment within the alternative assessment paradigm: revisiting the territory. The Curriculum Journal, 18(1), 39-56.

[13] Chen, J., \& Brown, G.T. (2013). High-stakes examination preparation that controls teaching: Chinese prospective teachers' conceptions of excellent teaching and assessment. Journal of Education for Teaching: International Research and Pedagogy, 39(5), 541-556.

[14] Chen, Q., May, L., Klenowski, V., \& Kettle, M. (2013). The enactment of formative assessment in English language classrooms in two Chinese universities: teacher and student responses. Assessment in Education: Principles, Policy \& Practice, 21(3), 271-285.

[15] China Ministry of Education (CMoE). (2007). College English Curriculum Requirements. Retrieved on 26 January 2017 from http://www.moe.edu.cn/edoas/website18/info34295.htm.

[16] Curriculum Development Council (CDC). (2002). Basic education curriculum guide: Building on strengths. Hong Kong: CDC

[17] Curriculum Development Council. (2007). English language curriculum and assessment guide (Secondary 4-6). Hong Kong: Hong Kong Government Printer.

[18] Curriculum Development Council (CDC). (2009). Senior Secondary Curriculum Guide (Secondary 4-6). Hong Kong: CDC.

[19] Ellis, R. A., Goodyear, P., Calvo, R.A., \& Prosser, M. (2008). Engineering students' conceptions of and approaches to learning through discussions in face-to-face and online contexts. Learning and Instruction, 18, 267-282.

[20] Furnham, A., Batey, M., \& Martin, N. (2011). How would you like to be evaluated? The correlates of students' preferences for assessment methods. Personality and Individual Differences, 50 (2), 259-263.

[21] Gibbs, G. (1999). Using assessment strategically to change the way students learn. In S. Brown and A. Glasner (Eds.), 
Assessment Matters in Higher Education: Choosing and Using Diverse Approaches (pp. 507-513). Buckingham: Open University Press.

[22] Gibbs, G., \& Simpson, C. (2004). Measuring the response of students to assessment: The assessment experience questionnaire. In C. Rust (Ed.), Improving Student Learning: Theory, Research and Scholarship (pp. 171-185). Oxford: OCSLD.

[23] Gijbels, D., \& Dochy, F. (2006). Students' assessment preferences and approaches to learning: can formative assessment make a difference? Educational Studies, 32 (4), 399-409.

[24] Gipps, C. (1994). Beyond testing: Towards a theory of educational assessment. London, UK: Falmer Press.

[25] Hargreaves, A., L. Earl, \& Schmidt, M. (2002). Perspectives on Alternative Assessment Reform. American Educational Research Journal, 39 (1), 69-95.

[26] Hue, M., Leung, C., \& Kennedy, K. (2015). Student perception of assessment practices: towards 'no loser' classrooms for all students in the ethnic minority schools in Hong Kong. Education Assessment, Evaluation Accountability, 27(2): $253-273$.

[27] Klenowski, V. 2009. "Assessment for learning revisited: an Asia-Pacific perspective." Assessment in Education: Principles, Policy \& Practice 16(30): 263-268.

[28] Lizzio, A., Wilson, K., \& Simons, R. (2002). University students' perceptions of the learning environment and academic outcomes: implications for theory and practice. Studies in Higher Education, 27(1): 27-51.

[29] McDowell, L., Wakelin, D., Montgomery, C., \& King, S. (2011). Does assessment for learning make a difference? The development of a questionnaire to explore the student response. Assessment \& Evaluation in Higher Education, 36(7): 749-765.

[30] MacLellan, E. (2001). Assessment for Learning: The differing perceptions of tutors and students. Assessment \& Evaluation in Higher Education 26(4): 307-318.

[31] OECD. (2011). Strong performers and successful reformers in education: lessons from PISA for the United States. Paris, FR: OECD.

[32] Pat-El, R. J., Tillema, H., Segers, M., \& Vedder, P. (2013). Validation of assessment for learning questionnaires for teachers and students. British Journal of Educational Psychology, 83(1), 98-113.

[33] Sadler, D.R. (1998). Formative assessment: revisiting the territory. Assessment \& Evaluation in Higher Education, 5(1), $77-84$.

[34] Segers, M., Gijbels,D., \&Thurlings, M. (2008). The relationship between students' perceptions of portfolio assessment practice and their approaches to learning. Educational Studies, 34(1), 35-44.

[35] Shepard, L.A. (2000). The Role of Assessment in a Learning Culture. Educational Researcher 29(7), 4-14

[36] Steadman, M. (1998). Using classroom assessment to change both teaching and Learning. New Directions for Teaching and Learning, 75(1), 23-35.

[37] Swaffield, S. (2011). Getting to the heart of authentic assessment for learning. Assessment in Education: Principles, Policy \& Practice, 18(3), 433-449.

[38] Taras, M., \& Davies, M.S. (2012). Perceptions and realities in the functions and processes of assessment. Active Learning in Higher Education, 14(1), 51-61.

[39] Torrance, H. (1995). The role of assessment in educational reform. In H. Torrance (Ed.) Evaluating Authentic Assessment: Problems and Possibilities in New Approaches to Assessment (pp.144-156). Buckingham: Open University Press.

[40] Trigwell, K., \& Prosser, M. (1991). Relating approaches to study and the quality of learning outcomes at the course level. British Journal of Educational Psychology, 61(1), 265-275.

[41] Turner, G., \& Gibbs, G. (2010). Are assessment environments gendered? An analysis of the learning responses of male and female students to different assessment environments. Assessment \& Evaluation in Higher Education, 35(6), 687-698.

[42] Visser, P., Krosnick, J., \& Lavrakas, P. (2000). Survey research. In H.T. Reis and C.M. Judd (Eds.), Handbook of Research Methods in Social and Personality Psychology (pp.223-252). Cambridge, UK: Cambridge University Press.

[43] Wiliam, D. (2011). What is assessment for learning? Studies in Educational Evaluation, 37(1), 3-14.

[44] Wiliam, D., and Thompson, M. (2008). Integrating assessment with instruction: What will it take to make it work? In C. A. Dwyer (Ed.), The Future of Assessment: Shaping Teaching and Learning (pp.53-82). Mahwah, NJ: Lawrence Erlbaum Associates.

[45] Zhu, C., M. Valcke, \& Schellens, T. (2008). A cross-cultural study of Chinese and Flemish university students: Do they differ in learning conceptions and approaches to learning? Learning and Individual Differences, 18 (1), 120-127.

Zhengdong Gan is an associate professor in the faculty of education at the University of Macau with research interests in second language education and assessment, and second language teacher education.

Fulan Liu $(\mathrm{PhD})$ is a professor at Jiangxi Normal University, China. She has obtained her PhD degree from the Education University of Hong Kong. Her research interest is second language acquisition and academic writing.

Chi Cheung Ruby Yang is Academic Coordinator (English Language) at City University of Hong Kong. She obtained her PhD in Applied Linguistics from Lancaster University (UK) in 2014. Her major research interests are English language teaching \& learning and teacher education. She has a range of publications in academic journals and presented in different local and international conferences. Besides these, she is actively involved in the editorial boards in a number of journals. 